\title{
Trends in incidence of anal cancer in Denmark
}

\author{
Morten Frisch, Mads Melbye, Henrik Møller
}

\begin{abstract}
Objective-To study long term trends in incidence of anal cancer in a well monitored, unselected population.
\end{abstract}

Design-Descriptive epidemiological study based on data from the Danish Cancer Registry.

Setting-Denmark, 1943-87.

Main outcome measures-Time related changes in anal cancer incidence according to sex, age, birth cohort, urban or rural residence, and marital status.

Results-The incidence of anal cancer remained fairly constant in the period $1943-57$ and was similar for men and women, but it increased 1.5 -fold among men and nearly tripled among women thereafter. Among men the incidence increased from 0.25 per 100000 population (world standardised) in 1958-62 to 0.38 in $1983-7(p=0.01)$ and among women from 0.28 to $0.74(p<0.01)$. The greatest increase was among residents of the capital (Copenhagen). During 1943-87 age specific trends increased in young and middle aged men and in all age groups among women. Men with anal cancer were significantly more likely throughout the study period to be unmarried than were patients with cancer of the colon (adjusted odds ratio $2 \cdot 7 ; 95 \%$ confidence interval 2.0 to 3.6$)$ and stomach $(2 \cdot 1 ; 1.5$ to $2 \cdot 8)$, but no association with marital status was found among women.

Conclusions-The distribution and incidence of anal cancer have changed appreciably since around 1960, especially among women, which indicates important aetiological changes. Changes in sexual behaviour may have facilitated the spread of a transmittable agent of aetiological importance. It has recently been suggested that cigarette smoking promotes anal cancer, and this finds indirect support in the synchronism between changes in anal cancer incidence and heavy smoking behaviour. Factors associated with homosexuality are likely to explain some of the cases among men.

Research Centre, Division for Cancer Epidemiology, Copenhagen, Denmark Morten Frisch, junior epidemiologist

Henrik Møller, biologist

Epidemiology Research Unit, State Serum Institute, Copenhagen, Denmark

Mads Melbye, professor

Correspondence and reprint requests to:

Dr Morten Frisch,

Epidemiology Research

Unit, State Serum Institute,

Artillerivej 5, DK-2300

Copenhagen S, Denmark.

BMF 1993;306:4 19-22 immunodeficiencies related to transplantation 1213 Furthermore, observations from epicentres of AIDS epidemic have suggested an increase in relation to the AIDS epidemic. ${ }^{14}$ In line with this, we and others have recently described anal epithelial abnormalities in a substantial proportion of homosexual men with immunosuppression induced by HIV and have documented a strong association between these abnormalities and the presence of human papillomavirus. ${ }^{15-18}$

So far, little has been published on the time trends for anal cancer, probably because of the limited access to long term data and those truly representative of populations. Using a national cancer registry that started 50 years ago, we examined trends of anal cancer in Denmark.

\section{Methods}

The Danish Cancer Registry has recorded all cases of cancer in Denmark since $1943 .{ }^{1920}$ As the object of our study was to identify clues to the aetiology of epidermoid anal cancer, we included only invasive non-adenocarcinoma and non-melanoma anorectal cancers. Because of changes in the use of coding systems in the Danish Cancer Registry, information about histology was obtained differently before and after 1978.

All original records on anal cancers coded according to a modified version of the seventh revision of the International Classification of Diseases (ICD7) from 1943 to 1977 were examined manually to avoid inclusion of adenocarcinomas $(n=47)$ and melanomas $(n=19)$. Apart from 446 cancers notified and coded as anal cancers (172 men and 274 women), some anal epidermoid carcinomas were notified as rectal cancers. To estimate the number of inappropriately notified anal cancers we examined all 2722 records of rectal cancers in 1950, 1960, and 1970 (8\% of rectal cancers 1943-77) and found 20 cases of epidermoid histology (six in $1950(0.8 \%)$, eight in $1960(0.9 \%)$, and six in $1970(0.6 \%)$; seven men and 13 women); thus we estimated that there were 244 misplaced cases of anal cancer (107 men and 137 women) in the entire period 1943-77. A search for epidermoid perianal cancers among the 183 trunkal skin cancers notified in 1950, 1960, and 1970 resulted in no additional cases.

Since 1978 the Danish Cancer Registry has used the International Classification of Diseases for Oncology (ICD-O). Topography codes used were 1541,1542 , 1543, and 1548, and histology codes were 80513$80523,80703-80763,80903-80953$, and 81203-81243. A total of 442 anal cancers were identified. To validate the registry data with respect to coding errors we examined a sample of 1003 rectal cancers $(9 \%$ of rectal cancers 1978-87) and found no misclassified anal cancers. As perianal skin cancer is coded with skin cancer of the trunk we manually examined records for all trunkal skin cancers (topography code 1735) with a histology of squamous cell carcinoma or transitional cell carcinoma $(n=221)$ and identified 57 epidermoid perianal cancers. In addition, we examined a sample of 1744 records of skin cancers $33 \%$ of trunkal skin 
cancers $1978-87)$ to estimate the number $(n=22)$ of other perianal skin cancers.

\section{STATISTICAL METHODS}

Age standardised incidence figures were calculated by direct standardisation, using as reference the world standard population..$^{21}$ Time trends and age at diagnosis were evaluated with a linear regression model by the method of least squares. ${ }^{22}$ To study potential associations with marital status we used a nested case-control design in which all individually identified anal cancer patients served as cases $(n=888)$ and all patients with colon cancer $(n=54207)$ and stomach cancer ( $n=58198)$ diagnosed during 1943-87 were used as independent control groups. Odds ratios were calculated and unconditional multivariate logistic regression models were used to adjust for potential confounding by age at diagnosis and calendar period. ${ }^{22}$

\section{Results}

Overall, 888 cases ( 303 men and 585 women) of anal cancer were identified; these had information on all variables. Another 266 anal cancers were calculated from the representative samples. This led to an estimated total of 1154 anal cancers (422 men and 732 women) diagnosed in Denmark during 1943-87.

Overall incidence-For both sexes, highly significant increases in the incidence of anal cancer (fig 1) were seen during 1943-87 ( $\mathrm{p}$ for trends $<0.001$ ). In the early decades age adjusted incidence rates were similar for men and women $(0 \cdot 20-0 \cdot 25$ per 100000 person years). Since around 1960 incidence rates nearly doubled in men and tripled in women, and most recent data

FIG 1-Incidence rates of anal cancer per 100000 world standardised population among Danish men and women 194387. Bars represent $95 \%$ confidence intervals
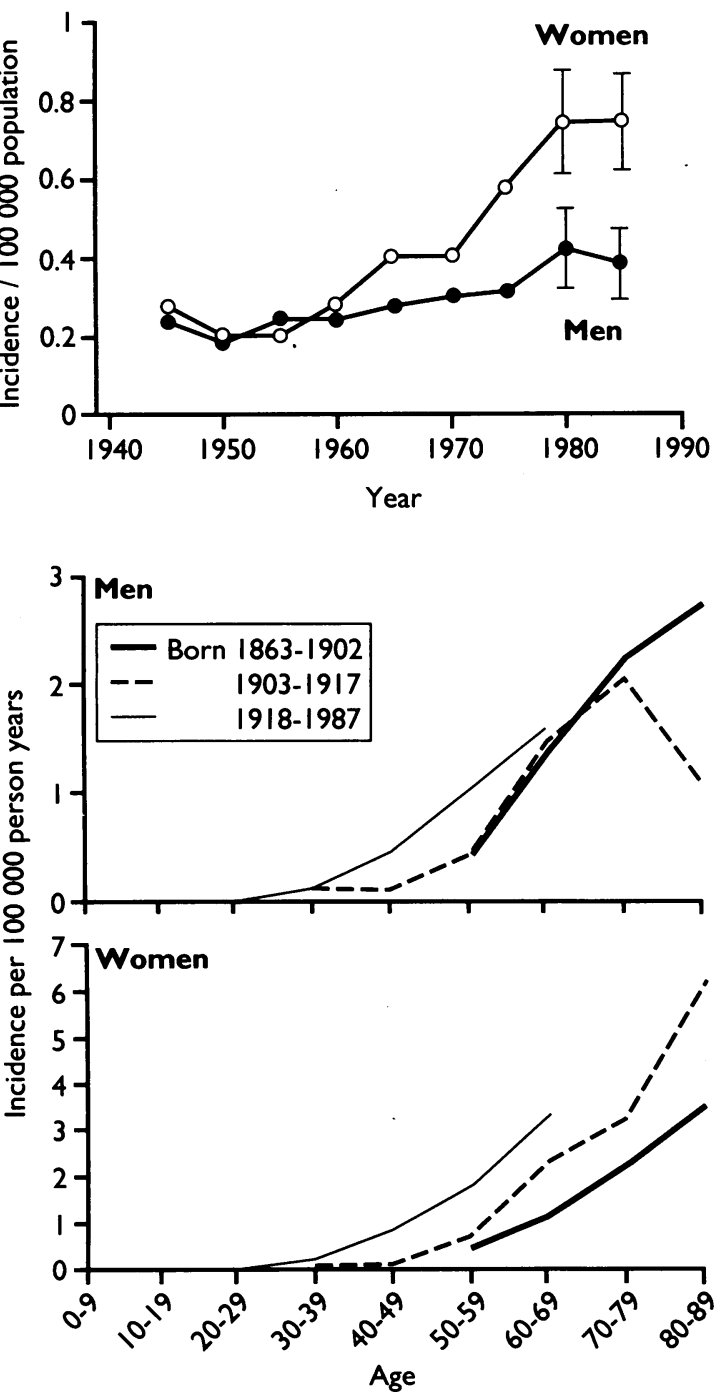

FIG 2-Age specific incidence rates of anal cancer in Denmark for men and women by birth cohort
(1983-7) give incidence rates of $0 \cdot 38 / 100000$ for men and $0 \cdot 74 / 100000$ for women (world standardised).

Age specific incidence according to period and birth cohort-Age specific incidence rates were compared for the periods 1943-62, 1963-77, and 1978-87. These periods contained approximately equal numbers of cases. In men the median age at diagnosis fell from 68 years in 1943-62 to 67 years in 1963-77 and 63 years in 1978-87 ( $\mathrm{p}$ for trend $<0.001$ ). Among women the median age at diagnosis remained fairly constant (67 years in 1943-62, 62 years in 1963-77, and 66 years in 1978-87). Subsequently, the cancer cases were divided into three birth cohorts of approximately equal size, covering the periods 1863-1902, 1903-17, and 1918-87 (fig 2). For men, the recent increase in incidence was seen almost exlusively among the young and middle aged and was confined to men in the most recent birth cohort (those born since 1918). For women, a pattern of gradual increase was seen by birth cohort in all age groups.

Incidence according to histology-The material was divided in three histological groups: 1 squamous cell carcinoma; 2 transitional cell carcinoma (including basal cell carcinoma); and 3 rare and unspecified histological types. Squamous cell carcinomas constituted the overwhelming majority of reported histological results throughout the study period, and the overall rise in anal cancer incidence could be explained almost entirely by the increase in incidence of squamous cell carcinoma, with only a minor contribution from transitional cell cancers in the latest part of the study period (data not shown).

Incidence according to geography-The material was analysed geographically comparing incidence in the capital area (Copenhagen and its suburbs) to that in the rest of Denmark (fig 3). In 1983-7 a quarter of the Danish population lived in the capital area. Among men in the capital the incidence of anal cancer remained stable around $0 \cdot 20-0 \cdot 25$ per 100000 until the late 1960s and increased appreciably hereafter. During the following 20 years a threefold increase in incidence occurred among men in Copenhagen and its suburbs ( $p$ for trend $=0.001$ ). Although at a much lower level, the incidence among men residing in the rest of Denmark also increased significantly, being $30-40 \%$ higher in 1983-7 than in 1943-7 ( $p$ for trend $<0.001$ ). From having similar rates in the early part of the study period, men residing in the capital area in 1983-7 had approximately $2 \cdot 5$-fold more anal cancer than men living in the rest of Denmark. Among women an appreciable increase was observed in both geographical areas during 1943-87 ( $\mathrm{p}$ for trend $<0.001)$. The overall increase in incidence was greater in the capital area than in the rest of Denmark, and by $1983-7$ this difference reached statistical significance (fig 3 ).

Incidence according to marital status-In total, $53(17 \%)$ of 303 men with anal cancer, $1790(7 \%)$ of 24420 men with colon cancer, and $2872(9 \%)$ of 33248 men with stomach cancer had never married. Among women the figures were $11 \%$ (64 of 585 anal cancer cases), $13 \%$ (3898 of 30787 colon cancer controls), and $12 \%$ (2859 of 24062 stomach cancer controls). Men with anal cancer were significantly more likely never to have married than were men with colon or stomach cancer (table). Odds ratios adjusted for age and period were 2.7 (95\% confidence interval 2.0 to 3.6$)$ for men and $1.0(0.8$ to 1.3$)$ for women, with colon cancer as control and $2 \cdot 1(1.5$ to $2 \cdot 8)$ for men and $1.2(0.9$ to 1.6$)$ for women with stomach cancer as control. The significant difference observed among men was consistent and showed rather similar odds ratios throughout the study period. Similarly, increased odds ratios were found for different age strata. 


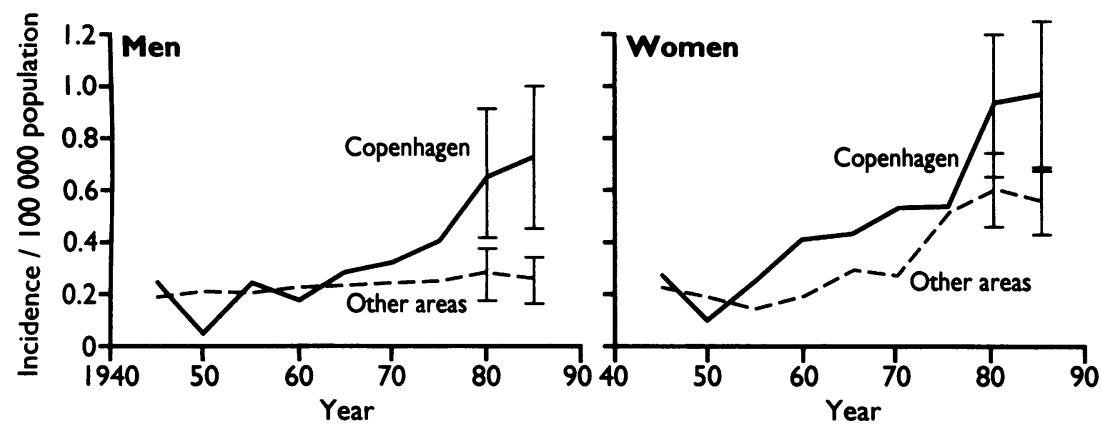

FIG 3-Incidence rates in men and women of anal cancer among residents of Copenhagen (including suburbs) and residents of other parts of Denmark, 1943-87. Bars represent $95 \%$ confidence intervals

Relative risk (odds ratios (95\% confidence intervals)) of never having been married among patients with anal cancer and controls with colon or stomach cancer, Denmark 1943-87

\begin{tabular}{|c|c|c|c|c|}
\hline & \multicolumn{2}{|c|}{ Men } & \multicolumn{2}{|c|}{ Women } \\
\hline & Anal $v$ colon cancer & Anal $v$ stomach cancer & Anal $v$ colon cancer & Anal $v$ stomach cancer \\
\hline \multicolumn{5}{|l|}{ Overall ${ }^{\star}$ : } \\
\hline Ever married & $1 \cdot 0$ & $1 \cdot 0$ & $1 \cdot 0$ & $1 \cdot 0$ \\
\hline Never married & $2.7(2.0$ to 3.6$)$ & $2.1(1.5$ to 2.8$)$ & $1.0(0.8$ to 1.3$)$ & $1.2(0.9$ to 1.6$)$ \\
\hline \multicolumn{5}{|l|}{ By periodt: } \\
\hline $1943-62$ & $2.2(1.1$ to 4.4$)$ & $1.9(1.0$ to 3.7$)$ & $1.8(1.1$ to 3.0$)$ & $2.2(1.3$ to 3.6$)$ \\
\hline 1963-77 & $3.3(2.1$ to 5.4$)$ & $2.7(1.7$ to 4.3$)$ & $0.7(0.5$ to 1.2$)$ & $0.8(0.5$ to 1.2$)$ \\
\hline $1978-87$ & $2.4(1.5$ to 3.9$)$ & $2.1(1.3$ to 3.4$)$ & $0.8(0.5$ to 1.2$)$ & $1.0(0.6$ to 1.5$)$ \\
\hline \multicolumn{5}{|l|}{ By ageł: } \\
\hline$<60$ Years & $2.3(1.4$ to 3.9$)$ & $1.8(1.1$ to 3.0$)$ & $0.8(0.4$ to 1.3$)$ & $0.8(0.4$ to 1.3$)$ \\
\hline 60-69 Years & $1.8(0.9$ to 3.6$)$ & $1.4(0.7$ to 2.7$)$ & $0.7(0.4$ to 1.2$)$ & $0.8(0.4$ to 1.3$)$ \\
\hline$\geqslant 70$ Years & $3.7(2.4$ to 5.9$)$ & $3.1(2.0$ to 5.0$)$ & $1.1(0.7$ to 1.6$)$ & $1.2(0.8$ to 1.8$)$ \\
\hline
\end{tabular}

*Adjusted for age at diagnosis (10 year age groups) and year of diagnosis ( 5 year periods).

tOdds ratio for people who never married for the specified period of diagnosis.

fOdds ratio for people who never married for the specified age groups.

\section{Discussion}

We observed a profound change in the pattern of epidermoid anal cancer. The increase in incidence started around 1960, at which time the difference in incidence between men and women also emerged. By 1983-7 women had twice the incidence of men. This finding is in line with a study from Sweden that also found a significant increase in incidence during the shorter period $1970-84$, resulting in twice the incidence in women as in men. ${ }^{23}$ About 1960 a dramatic difference in incidence emerged between residents of Copenhagen and residents of the rest of Denmark. In Sweden the steepest increase was also observed in the most densely populated cities, indicating a strong association between certain urban lifestyle factors and anal cancer. ${ }^{23}$

We made a considerable effort to adjust for problems related to potential misclassification of anal cancers. A proportion of the cases from the period 1943-77 was derived as an estimate based on the rate of misplaced cancers and could, in theory, contribute importantly to the increasing trends of anal cancer. However, the proportion of cases deriving from this estimate of misplaced anal cancers actually decreased during 1943-77. Therefore, the observed trends were almost exclusively explained by the $400 \%$ increase during 1943-77 in cancers accurately coded as anal.

\section{RISK FACTORS}

In a recent study we found women with anal cancer to have a high risk of having had cervical intraepithelial neoplasia or invasive cervical cancer diagnosed previously. ${ }^{10}$ This risk was at least as high as for patients with vulval cancer, indicating the potential for shared aetiological factors in these anogenital cancers. A subsequent study of second cancers following anal and cervical cancer found further support for this aetiological link. ${ }^{24}$ Sexual behaviour and infection with human papillomavirus seem important in addition to smoking in the genesis of cervical cancer and may also be involved in the aetiology of anal cancer. ${ }^{25}$ In contrast with what has been reported for cervical cancer patients, the lifetime number of sexual partners has not been found of significant, independent importance in the few case-control studies of anal cancer published so far. ${ }^{679}$ Although anal intercourse may play some part it does not seem to be a necessary activity for the development of anal cancer. In the study by Holly et al $18 \%$ of female cases and $14 \%$ of controls reported ever having had anal intercourse. ${ }^{6}$ In another case-control study Daling et al found a significant association between anal intercourse and anal cancer among men but not among women.9 More Danish women than men practise receptive anal intercourse, and it seems this sexual practice has become more prevalent during the past decades. ${ }^{26}$ This parallels our finding of a higher incidence among women, but does not necessarily imply a causative role of anal intercourse. The increasing incidence of anal cancer we observed was apparent well before the sexual liberation in Denmark in the late 1960 s and early $1970 s,{ }^{26}$ but the possibility exists that a potentially carcinogenic agent has become increasingly common in the anal region as a result of changing sexual habits.

Marital status was not important for the development of anal cancer among women. However, throughout 1943-87 men who had never married were at increased risk of anal cancer compared with colon or stomach cancer. Previous studies have reported an association between men who had never married and anal cancer ${ }^{124}$ and argued that these findings reflected an association with male homosexuality. Because of the early establishment of the Danish Cancer Registry we were able to show that this potential association dates back to at least the $1940 \mathrm{~s}$. Therefore, the potential influence of male homosexuality on the development of anal cancer does not seem to be a new phenomenon.

Smoking as a risk factor for anal cancer has been suggested by Daling and others. ${ }^{6-9}$ Indeed, changed smoking habits might explain some of the observed recent increase in anal cancer incidence. The percentage of Danes who smoke has decreased, but that of heavy smokers ( $>15$ cigarettes/day) rose between 1953 and 1991 from $6 \%$ to $22 \%$ in men and from $1 \%$ to $14 \%$ in women. ${ }^{28}$ During this period there was a greater proportion of heavy smokers in the capital area, which is in agreement with the observed geographical distribution of patients in the present study. The temporal proximity between changes in smoking habits and changes in anal cancer incidence supports a late stage or promotional role for smoking. ${ }^{8}$ However, a simplistic model based exclusively on smoking habits fails to explain the higher incidence in women, since women do not smoke as heavily as men. ${ }^{28}$

HIV infection has been mentioned as a possible cofactor in the increasing incidence of anal cancer in some areas of the United States. ${ }^{14}$ Our study shows that the increase in anal cancer incidence started 20-25 years before the first AIDS patient in Denmark was diagnosed in $1981 .{ }^{29}$ This, combined with the female predominance of this cancer, indicates that HIV is unlikely to have had any role so far in anal cancer development in Denmark. However, evidence is accumulating that, as in cervical cancer, human papillomavirus may have a causal association with anal cancer. ${ }^{69152530}$ Certainly the considerable rate of detection in the anal region of high risk types of human papillomavirus along with anal intraepithelial neoplasia in immunosuppressed homosexual men ${ }^{16}{ }^{17}$ warrants further attention. It seems plausible that the life expectancy of people infected with HIV is too short today for invasive anal cancer to develop, but better treatment regimens might one day change this picture.

\section{SUMMARY}

The increase in anal cancer incidence seen par- 
ticularly in women and residents of the capital argues in favour of recent important changes in behavioural or environmental factors of importance to the development of this cancer. The contemporary changes in smoking habits and incidence of anal cancer would support the hypothesis that the anus is yet another site with increased susceptibility to carcinogens resulting from smoking. Recent changes in sexual habits also coincide with the trends in anal cancer incidence and suggest, as with cervical cancer, that an infectious agent is involved. Finally, men who had never married were found at increased risk since the 1940s, indicating a potential association with male homosexuality.

Support for this study was given by the Danish Cancer Society (grant No 90-7620). We are indebted to Dr HansOlov Adami, Cancer Epidemiology Unit, University Hospital, Uppsala, Sweden, and Dr Robert J Biggar, Environmental Epidemiology Branch, National Cancer Institute, Bethesda, USA, for their comments on the study's design and critical review of the manuscript.

1 Peters RK, Mack TM. Patterns of anal carcinoma by gender and marital status in Los Angeles county. Br f Cancer 1983;48:629-36.

2 Wexner SD, Milsom JW, Dailey TH. The demographics of anal cancer are changing. Dis Col Rect 1987;30:942-6.

3 Biggar RJ, Burnett W, Mikl J, Nasca P. Cancer among New York men at risk of acquired immunodeficiency syndrome. Int 9 Cancer 1989;43:979-98.

4 Austin DF. Etiological clues from descriptive epidemiology: squamous carcinoma of the rectum or anus. National Cancer Institute Monographs carcinoma of the

5 Daling JR, Weiss NS, Klopfenstein LL, Cochran LE, Chow WH, Daifuku R. Correlates of homosexual behaviour and the incidence of anal cancer. $¥ A M A$ 1982:247:1988-90.

6 Holly EA, Whittemore AS, Aston DA, Ahn DK, Nickoloff BJ, Kristiansen JJ Anal cancer incidence: genital warts, anal fissure or fistula, hemorrhoids, and smoking. $7 N C I 1989 ; 81: 726-3$

7 Holmes F, Borek D, Owen-Kummer M, Hassanein R, Fishback J, Behbehani A, et al. Anal cancer in women. Gastroenterology 1988;95:107-11.

8 Daling JR, Sherman KJ, Hislop TG, Maden C, Mandelson MT, Beckmann $\mathrm{AM}$, et al. Cigarette smoking and the risk of anogenital cancer. Am J Epidemiol 1992;135:180-9.

9 Daling JR, Weiss NS, Hislop TG, Maden C, Coates RJ, Sherman KJ, et al. Sexual practices, sexually transmitted diseases, and the incidence of anal cancer. N Engl f Med 1987;317:973-7.

10 Melbye M, Spregel P. Aetiological parallel between anal cancer and cervical cancer. Lancet 1991;338:657-9.

11 Zur Hausen $\mathrm{H}$. Papillomaviruses in anogenital cancer as a model to understand the role of viruses in human cancers. Cancer Res 1989;9:4677-81.

12 Penn I. Cancers of the anogenital region in renal transplant recipients. Cancer 1986;58:611-6.
13 Blohme I, Brynger H. Malignant disease in renal transplant patients. Transplantation 1985;39:23-5.

14 Hever D, Desmond S, Volberding P, Kahn J. Changing prevalence of malignancies in men at San Francisco General Hospital during the HIV epidemic. Fifth international conference on AIDS, Montreal, 1989. Ottawa: International Development Research Centre, 1989: abstract WBO19.

15 Beckmann AM, Daling JR, Sherman KJ, Maden C Miller BA, Bates RJ, et al. (Int $\mathcal{I}$ Cancer 1989;43: 1042-9.

16 Melbye M, Palefsky J, Gonzales J, Ryder LP, Nielsen H, Bergmann O, et al. Immune status as a determinant of human papillomavirus detection and its association with anal epithelial abnormalities. Int 7 Cancer 1990;46:203-6.

17 Caussy D, Goedert JJ, Palefsky J, et al. Interaction of human immunodeficiency virus and papillomaviruses: association with anal epithelial abnormality in

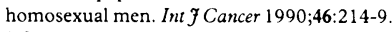

18 Palefsky JM, Gonzales J, Greenblatt RM, Ahn DK, Hollander H. Ana intraepithelial neoplasia and anal papillomavirus infection among homosexual males with group IV HIV disease. FAMA 1990;263:2911-6.

19 Storm HH. The Danish Cancer Registry, a self-reporting national cancer registration system with elements of active data collection. In: Jensen $\mathrm{OM}$ Parkin DM, Maclennan R, Muir CS, Skeet RG, eds. Cancer registration principles and methods. Lyons: International Agency for Research on Cancer, 1991:220-36. (IARC Scientific Publication No 95.)

20 Wagner G. History of cancer registration. In: Jensen OM, Parkin DM Maclennan R, Muir CS, Skeet RG, eds. Cancer registration, principles and methods. Lyons: International Agency for Research on Cancer, 1991:3-6. (IARC Scientific Publication No 95.)

21 Smith P. Comparison between registries: age-standardized rates. In: Muir C Waterhouse J, Mack T, Powel J, Whelan S, eds. Cancer incidence in five continents. Vol 5. Lyons: International Agency for Research on Cancer, 1987:790-5. (IARC Scientific Publications No 88.)

22 SAS Institute. SAS/STAT users guide, version 6 . Vol 2, 4th ed. Cary, NC: SA Institute, 1989:1325-1456

23 Goldman S, Glimelius B, Nilsson B, Påhlman L. Incidence of anal epidermoid carcinoma in Sweden 1970-1984. Acta Chir Scand 1989;155:191-7.

24 Rabkin CS, Biggar RJ, Melbye M, Curtis RE. Second primary cancers following anal and cervical carcinoma: evidence of shared etiologic factors. Am F Epidemiol 1992;136:54-8.

25 Daling JR, Sherman KJ. Relationship between human papillomavirus infection and tumours of anogenital sites other than the cervix. In: Munoz N, Bosch FX, Shah KV, Meheus A, eds. The epidemiology of cervical cancer and human papillomaviruses. Lyons: International Agency for Research on and human papillomaviruses. Lyons: International Agency

26 Melbye M, Biggar RJ. Interactions between persons at risk for AIDS and the general population in Denmark. Am f Epidemiol 1992;135:593-602.

27 Scholefield JH, Thornton Jones H, Cuzick J, Northover JMA. Anal cancer and marital status. Br f Cancer 1990;62:286-8.

28 Osler M. Smoking habits in Denmark from 1953 to 1991: a comparative analysis of results from three nationwide health surveys among adult Danes in 1953-54, 1986-87 and 1990-91. Int $f$ Epidemiol 1992;21:862-71.

29 Melbye M, Biggar RJ, Ebbesen P, Sarngadharan MG, Weiss SH, Gallo RC, et al. Seroepidemiology of HTLV-III antibody in Danish homosexual men: prevalence, transmission, and disease outcome. BMf 1984;289:573-5.

30 Palefsky JM, Holly EA, Gonzales J, Berline J, Ahn DK, Greenspan JS Detection of human papillomavirus DNA in anal intraepithelial neoplasia and anal cancer. Cancer Res 1991;51:1014-9.

(Accepted 26 November 1992
MRC Environmental Epidemiology Unit Southampton General Hospital, Southampton SO9 4XY

D J P Barker, professor C Osmond, statistician S J Simmonds, research assistant

G A Wield, systems analyst

Correspondence to:

Professor Barker.

$B M 7$ 1993;306:422-6

\title{
The relation of small head circumference and thinness at birth to death from cardiovascular disease in adult life
}

\author{
D J P Barker, C Osmond, S J Simmonds, G A Wield
}

\begin{abstract}
Objective-To determine how fetal growth is related to death from cardiovascular disease in adult life.

Design-A follow up study of men born during 1907-24 whose birth weights, head circumferences, and other body measurements were recorded at birth.

Setting-Sheffield, England.

Subjects-1586 Men born in the Jessop Hospital.

Main outcome measure-Death from cardiovascular disease.

Results-Standardised mortality ratios for cardiovascular disease fell from 119 in men who weighed 5.5 pounds $(2495 \mathrm{~g})$ or less at birth to 74 in men who weighed more than 8.5 pounds $(3856 \mathrm{~g})$. The fall was significant for premature cardiovascular deaths up to 65 years of age $\left(\chi^{2}=5 \cdot 0, p=0 \cdot 02\right)$. Standardised mortality ratios also fell with increasing head circumference $\left(\chi^{2}=4.6, p=0.03\right)$ and increasing ponderal index (weight/length $\left.{ }^{3}\right)\left(\chi^{2}=3 \cdot 8, \mathbf{p}=0.05\right.$; for premature deaths $\left.\chi^{2}=6 \cdot 0, p=0 \cdot 01\right)$. They were not related to the duration of gestation. Among men for
\end{abstract}

whom the ratio of placental weight to birth weight was in the highest fifths the standardised mortality ratio wàs 137 .

Conclusion-These findings show that reduced fetal growth is followed by increased mortality from cardiovascular disease. They suggest that reduction in growth begins early in gestation. They are further evidence that cardiovascular disease originates through programming of the body's structure, physiology, and metabolism by the environment during fetal life. Maternal nutrition may have an important influence on programming.

\section{Introduction}

People who had low growth rates during fetal life and infancy have high death rates from ischaemic heart disease. Among 5654 men born in six districts of Hertfordshire, England, during 1911-30 death rates from ischaemic heart disease fell progressively between those with the lowest and highest weights at 1 year. The death rates in those who weighed 18 pounds $(8165 \mathrm{~g})$ or less at 1 year were almost three times greater 